\title{
LINGUAGEM, OBJETO E INTENSÃO: UMA LINHA INVESTIGATIVA DO INTENSIONALISMO NÃO CONCILIÁVEL COM A METAFÍSICA
}

\begin{abstract}
LUCAS RIBEIRO VOLLET ${ }^{1}$
RESUMO: A política de policiamento rigoroso dos atributos e outros esquemas de individuação feita por W. Quine - em Relatividade Ontológica e outros ensaios (1969) - guarda uma semelhança argumentativa com a polarização da ciência contra a antropomorfização do discurso teórico. Apesar de disfarçada, essa semelhança retórica encontra eco em trechos de Falando de Objetos e em Dois Dogmas do Empirismo. Nesse artigo, seguindo a sugestão de Ruth B. Marcus de que o discurso intensional se distingue do extensional por uma pretensão de força da identidade invocada, iremos propor que Quine está preso a um preconceito cientificista antigo, cuja característica principal é a incapacidade de reconhecer - ou relegar a recursos de uma época pré-científica (antropomórfica) - meios não ortodoxos ou informais de consolidar a força dos padrões de identidade da linguagem. Isso nos ajudará a sugerir um argumento em que a discussão sobre as intensões envolve uma miscigenação com problemas hermenêuticos e históricos sobre o significado e a interpretação.
\end{abstract}

PALAVRAS-CHAVE: Linguagem, Intensão, Antropomorfismo.

ABSTRACT: W. Quine's policy of strict monitoring of attributes and other individuation schemes - in Ontological Relativity and other essays (1969) - bears an argumentative resemblance to the old opposition of science against the anthropomorphization of theoretical discourse. Although disguised, this similarity is echoed in excerpts of Speaking of Objects and in Two Dogmas of Empiricism. In this article, following the suggestion of Ruth B. Marcus that the intensional discourse is distinguished from the extensional one by a pretension of strength of the invoked identity, we will propose that Quine is bound by an ancient scientific prejudice, whose main characteristic is either the inability to recognize unorthodox or informal means of consolidating the strength of the language's identity patterns, or the inclination to regard those strategies and means to a pre-scientific (anthropomorphic) attitude. This will help us to suggest an argument in which the discussion of intensions involves miscegenation with hermeneutical and historical problems about meaning and interpretation.

KEYWORDS: Language, Intension, Anthropomorphism.

\section{Quine e o policiamento do antropomorfismo presente na padronização linguística}

A linguagem é um instrumento humano cujas potencialidades são difíceis de se conciliar com algumas de nossas crenças científicas. Quando pensamos nos poderes de padronização e universalização da linguagem, inclusive sua capacidade de nos autorizar a construir nossos

\footnotetext{
${ }^{1}$ Doutor em Filosofia pela Universidade Federal de Santa Catarina (UFSC). E-mail: luvollet@gmail.com.
} 
próprios esquemas conceituais e arriscar nossas próprias hipóteses sobre conexões necessárias, pensamos nela como um objeto difícil de ser catalogado entre os itens do mundo. A língua natural ou sistema de signos codifica nossas teorias sobre a identidade, de modo que ela traz um universo de compreensão novo a ser explicado pelas nossas teorias científicas. Ela gera essa inflação. Aumenta o número de coisas a serem explicadas. Se a transcrição dos instrumentos pragmáticos que a linguagem nos dá para criar aproximações indutivas é institucionalizada quando se transforma em código, é também aqui que ela se torna ameaçadora. O mundo começa a se povoar de convenções, que, reificadas, exercem sobre o humano um verdadeiro império de superstição. Toda instituição contém mistérios antropomórficos que escondem a política por traz do enigma. Portanto, é quando criamos código que cruzamos o limite perigoso, que fazemos aquela transição, sempre acusada por Quine, do científico ao não tão científico (ou o metafísico):

a tradução reconhece a expressão nativa, na prática, como uma expressão para anunciar coelhos. Mas o passo subsequente do linguista, no qual ele impõe seu próprio padrão de pôr objetos, sem garantia alguma, ocorre quando ele equaciona a expressão nativa ou alguma parte dela ao termo coelho. (1980, p. 117)

Uma forma de desafiar essa prescrição é perguntar qual a natureza do perigo anunciado nessa padronização. Pois aqueles inclinados a uma resposta intuitiva, onde os tipos naturais são vistos como termos que entram na nossa linguagem pela sua contribuição para organizar nossa referência, não formarão oposição firme a esse passo apenas porque ele lembra uma inclinação metafísica. Principalmente, porque a memória é fraca. Já não lembramos com o mesmo sentimento de ameaçados dos vícios da metafísica escolástica. Mas o perigo parece surgir quando se é um filósofo com boa memória e se tenha estudado toda a história das polêmicas entre o essencialismo, o racionalismo e o empirismo. E se se é um cientista que estudou filosofia, há mais chances de amadurecer a visão desse perigo, pois os modos de identificação que lançam mão de recursos não empíricos guardam um parentesco com as antigas entidades teleológicas e sobrenaturais que assombraram a ciência medieval. Nosso discurso modal, contrafactual e mesmo o discurso teórico mais inofensivo são inevitáveis se não temos outra opção para fixar referências e discutir conexões necessárias. Mas eles têm a característica de obscurecer a lógica, não apenas porque entretêm enigmas sobre a permutabilidade salva veritate e a sustentabilidade semântica de enunciados como o do mentiroso, mas porque confundem o âmbito das soluções empíricas e científicas com o de problemas não tão científicos (ou francamente metafísicos). Para Quine, em Falando de Objetos, "atitudes proposicionais e atributárias pertencem ao universo cotidiano das esperanças, temores e propósitos; a ciência 
causal se arranja bem sem ele" (1980, p. 130). Em Dois Dogmas, o professor afirma: "na questão do embasamento epistemológico, os objetos físicos e os deuses diferem apenas em grau, não em espécie. Ambos os tipos de entidades integram nossa concepção apenas como supostos culturais" (1980, p. 247).

É sintomático que a antropomorfização da lógica seja recebida como um problema de maior gravidade, para filósofos analíticos (ou ligados a essa tradição pela polêmica), do que os paradoxos de Russell e teoremas da incompletude. John Etchemendy em 1999 (The Concept of Logical Consequence) sustentou a tese de que o trabalho de Alfred Tarski falhou em conciliar as caracterizações sintáticas do conceito de consequência lógica e as relações de consequência genuínas para as linguagens de primeira ordem:

Aplicar a explicação modelo-teórica, eu afirmo, não é uma técnica mais confiável para esquadrinhar os argumentos genuinamente válidos de uma linguagem do que aplicar uma definição puramente sintática. (...). Desnecessário dizer que essa conclusão nos pressiona a reavaliar o significado intuitivo do teorema da completude de Goedel, assim como o fracasso de resultados semelhantes quando nos movemos, por exemplo, à lógica de segunda-ordem. $(1999, \text { p. } 6)^{2}$.

A afirmação de Etchemendy reflete uma avaliação generalizada das dimensões corretas das ambições lógicas da primeira metade do século XX. Os esforços analíticos para limpar a parte intensional e não mecanicamente previsível da lógica só são recompensados se nos restringirmos a fragmentos de linguagem previsíveis, mas triviais: "construir uma teoria do significado não é um empreendimento científico, mas na ciência o mesmo desafio surge: você pode construir uma teoria de sucesso para o caso especial, e você torce para que se estenda ao caso geral, mas você não pode contar com isso" (Dummet, 1994, p. 178) ${ }^{3}$. Isso apoia a suspeita de que a cisma é profissional. É uma antiga divergência, que remonta à cisão entre filosofia analítica e continental. Não parece aos filósofos analíticos um incômodo o obscurecimento da lógica derivado e demonstrado em seus próprios sistemas axiomáticos. Mas se levantam apressados se alguém arrisca supor que existem na lógica infiltrações normativas e influências históricas e hermenêuticas. O medo de dilemas e antinomias é menor do que o medo de fantasmas. O segundo tipo de irracionalidade os preocupa mais que o primeiro - apesar do primeiro ser muito mais inconsciente. Pois no segundo caso o que está em jogo é político e, justamente, a sobrevivência histórica de sua tradição. A tendência de Quine a atitudes de conciliação, em casos semelhantes, é bastante bem documentada no término de seus artigos, por exemplo em Dois Dogmas:

\footnotetext{
${ }^{2}$ Nossa tradução

${ }^{3}$ Origins of Analytical Philosophy, nossa tradução.
} 
Trata-se da questão de saber se devemos quantificar com respeito às variáveis que tomam classes como valor. Ora, Carnap sustentou que isso não é uma questão fatual, mas de escolha de uma forma linguística conveniente, um esquema ou estrutura conceitual conveniente à ciência. Posso concordar com isso, com a condição de que o mesmo seja concebido no que diz respeito às hipóteses científicas em geral. (QUINE, 1980, p. 248)

Quine termina também o artigo Falando de Objetos um pouco divido e tentando mostrar a face pouco radical. Ele acredita que entidades atributivas, entendidas sem critério de identidade, mais ou menos como os "temores" e "expectativas" que criam caminhos semióticos e projeções mágicas, poderiam “principiar a evoluir”. Esse principiar certamente, para ele, tem o significado de um evoluir para o século XVIII, para o colo de David Hume. Mas, se Hume ainda tinha escrúpulos metafísicos ligados a obrigações práticas que devíamos a uma concepção liberal de humanidade, Quine está mais próximo de um cínico completo, associando os objetos físicos a uma mitologia adotada pela sua utilidade prática: "o mito dos objetos físicos é epistemologicamente superior aos outros mitos porque provou ser mais eficiente" (1980, p. 247). Quine deixa, portanto, um espaço para zombarmos de nossa própria pretensão de supremacismo científico, mas nos associa a uma espécie de culto antropomórfico um pouco mais evoluído do que os ritos das tribos que ainda obedecem a tabus e idolatram totens. A pergunta que nós colocamos para desafiar essa insinuação é: existe alguma conexão irredutível entre o discurso modal, atributivo e contrafactual presente nas atitudes proposicionais e uma era de irracionalidade pré-científica? Não há maneiras de ser anti-metafísico sem comprar um discurso cientificista e naturalista particularmente estéril? Iremos avançar uma discussão que possa criar condições para responder essas perguntas.

\section{Tentativas de resgate da metafísica e seus problemas}

A história da filosofia analítica, contada do avesso, pela perspectiva de pensadoras como Ruth Barcan Marcus e pensadores como Saul Kripke, reinterpretaria os primeiros esforços de Bertrand Russell como uma obsessão quase supersticiosa. O regime de política intolerante do cavalheiro Inglês contra intensões, classes e outros conceitos fortes de identidade o forçaram a varrer qualquer vestígio de relação lógica que pudesse - quer por influência gramatical (analítica), quer por influência científica (sintética a priori) - ser projetada sobre matérias de fato ou investigações empíricas. Russell foi um pensador alimentado pela visão de enigmas e paradoxos. Seus projetos de limpar a gramática e proibir formas não demonstrativas de identificação eram coassociados ao projeto de impedir que a lógica pudesse inflacionar de 
dentro para fora, se tornando por demais inclusiva, ao ponto de permitir às suas regras que regulem contra si mesmas. Quando W.Quine assimilou a questão da identidade leibniziana a um problema relativo ao grau de riqueza normativo da linguagem para hospedar os últimos resultados da ciência, esse objetivo teria ganhado sua expressão mais dominante. De modo que a reinterpretação desse período precisava eleger uma estratégia efetiva de atacar o seu ponto fraco. Essa foi feita pela perspectiva da tentativa de reabilitar certos conceitos perdidos.

Os paradoxos sobre contextos intensionais, recapitulemos, foram popularizados pela obra de Russell, On Denoting. Nela o autor ensinava as consequências enigmáticas seguidas de quando a verdade ou a falsidade de uma sentença como "W. Scott é o autor de Waverley" passa a fixar as condições de sua dependência de verdade em questões sobre a curiosidade de George IV: "quando dizemos 'George IV desejava saber se Scott era o autor de Waverley, normalmente queremos dizer 'George IV desejava saber se um e somente um homem escreveu Waverley, e George IV desejava saber se Scott era esse homem" (1978, p. 11). Russell empregou uma descomunal energia para tornar isso público: que existe uma relação lógica entre as evidências e a atitude epistêmica, de um modo que a gramática ordinária tende a mascarar ou traduzir por problemas de codificação a priori: "cada observação particular conta algo ao observador. Pode ser difícil expressar em palavras exatamente o que se pode aprender com essa observação, mas não é impossível" (Russell, 1978, p. 280).

Ao converter atribuições de necessidade a predicados de funções proposicionais ${ }^{4}$, Russel levava a um limite de radicalidade a tese clássica de que as proposições necessárias não têm um "conteúdo necessário", mas o são assim em virtude de sua forma condicional, como afirmado por Quine (Necessary Truth):

O advérbio 'necessariamente' é aplicado somente indiretamente a eventos e estados particulares, e apropriadamente somente a conexões condicionais em sua totalidade. Eu apresentei esse 'necessariamente' (...) como uma simples alusão a alguma regularidade mais ou menos insinuada (...). A tese de que necessidade não é mais do que regularidade foi exposta por David Hume há mais de dois séculos atrás (QUINE, 1994, p. 71).

A necessidade da identidade, a intuitividade das diferenciações contrafactuais efetuadas por proposições modais, a capacidade de representar na linguagem a referência a indivíduos em pontos diferentes do tempo, foram pressionando pensadores a repensar o que o empirismo radical havia perdido em sua campanha de extremismo. Entre eles podemos citar Ruth Marcus, Saul Kripke e David Lewis. Segundo Dummet: "A sinopse dos editores de Naming and

\footnotetext{
${ }^{4}$ Ver A Filosofia do Atomismo Lógico: "Em toda filosofia tradicional aparece um título de 'modalidade', que discute o necessário, o possível e o impossível como propriedades das proposições, ao passo que de fato são propriedades de funções proposicionais. Proposições são apenas verdadeiras ou falsas" (1978, p. 96)
} 
Necessity fala da contemporânea florescente metafísica essencialista como largamente devedora ao ímpeto do artigo de Kripke" (1981, p. 599). A nova metafísica tem algumas características principais, que iremos mencionar apenas na medida em que podem ser reivindicadas para se opor ao ceticismo de Quine. Antes de tudo, os pensadores ligados a essa nova fase da filosofia analítica sugerem opções semânticas para dar visibilidade a representações contrafatuais ou temporais. A teoria dos nomes próprios rígidos, sugerida por Marcus e Kripke, supunha a possibilidade de fixar a mesma referência em diferentes ocasiões, isto é, em ocasiões divergentes de verificação e falseamento das sentenças (mundos possíveis). Sobre isso, Dummet disse: “a noção de designador rígido é explicada em termos de identidade. Ela adquire substância quando avançamos para explicar a identidade transmundana" (DUMMETT, 1981, p. 599) $^{5}$. Acrescentar itens técnicos à linguagem para melhorar seu modo de fazer referência pode ter um componente convencional simples como o de batizar, mas dificilmente podemos reduzir a questão sobre se alguém contou a mesma pessoa duas vezes isto é, em termos francos: se ela se confundiu - ao batizado. A ambiguidade, a confusão, o equívoco, não são simples problemas técnicos. Por isso não é realista solucioná-los através de artifícios. Eles são formas sintomáticas de exprimir problemas filosóficos, a respeito dos fundamentos de nossos sistemas de categorias, que se tornaram impróprios ou limitados para representar as concepções científicas atuais.

Por fim, a possibilidade de definir logicamente diferenciações modais, dando um conteúdo à diferença a como algo seria se p e se não-p, ou como deveria ser caso p, em oposição a se não-p, etc., é uma simplificação semântica do problema cujas vantagens estão correlacionadas à perda de profundidade das conexões assim entrelaçadas. É verdade que, em circunstâncias normais, somos capazes de afirmar que, se p e não-p, temos uma contradição. Mas isso não é o caso em circunstâncias modais que consideram condições contrafatuais. A interpretação semântica a partir de mundos possíveis deu uma interpretação às obscuras identidades e divergências de verdade modais e contrafactuais que não desrespeita a extensionalidade. Mas se tornou um artifício técnico, e não uma verdadeira tese metafísica. Nas palavras de Dummet, que acredita que o recurso aos nomes próprios não torna nossas concepções de necessidade mais claras ou mais metafisicamente robustas:

Se o mecanismo de rigidez vai ser adotado, ou se o escopo vai fazer todo o trabalho, não é de primária importância. (...) O que é de primária importância é a origem comum em termos da qual ambos os mecanismos são explicados: a aplicação a um indivíduo atual de um predicado contrafatual. (...) a questão é se há princípios gerais uniformes governando essas identificações em todos

\footnotetext{
${ }^{5}$ Nossa tradução.
} 
os casos, e o que eles são. (...). Minha opinião é que não há tais princípios gerais uniformes. (DUMMET, 1981, p. 600)

\section{Uma terceira opção: o intensionalismo sem metafísica presente na codificação da linguagem.}

Mas o que faltou à campanha neometafísica? O que os pensadores neo-essencialistas dos mundos possíveis não sabiam é que havia uma terceira saída. Ou, se sabiam, não a quiseram explorar. A tradição continental da filosofia sempre avançou sua própria linhagem de antimetafísica, sem depender de um cientificismo estéril regido por conselhos de Occam. O que estava em questão era o grau de força que poderíamos reivindicar da linguagem - entendida como estrutura completa e sincrônica de material analógico, ou como sistema para predição de sentenças possíveis - para nossas proposições sobre identidade, semelhança, congruência e esquematização analógica. O problema da rigidez, portanto, não é, como parecia a Dummet, apenas relativo às convenções semânticas para lidar com o conceito de necessidade ou identidade, mas sim à força com que a identidade resiste entrincheirada nessa linguagem. $\mathrm{O}$ fato de que uma linguagem tenha recursos e instrumentos para manter rígida a diferença transmundana não é um fato arbitrário. Mostra algo sobre essa linguagem, sobre sua força para defender seus conceitos de analiticidade. Como disse Marcus Barcan:

se a identidade é apropriada a proposições, atributos, classes, tanto quanto aos tipos inferiores de indivíduos, então qualquer enfraquecimento da relação de identidade com respeito a qualquer dessas entidades pode ser pensado como uma extensionalização dessa linguagem (1993, p. 6).

Na introdução do livro que reuniu seus ensaios em 1991, Ruth Barcan Marcus observou que "uma linguagem ou teoria é considerada como extensional pela medida em que relações de equivalência robustas podem ser reduzidas a outras mais fracas" (1991, p. xiii). Essa simples e elegante definição, já mencionada em outro trecho do mesmo livro, desafia a posição de que colocar um problema de interpretação como intensional ou como extensional seria uma alternância entre uma opção metafísica ou mística e outra empírica e científica. O que gerou a polêmica detonadora desse estereótipo polarizador grosseiro foi o fato de que ela revivia uma antiga dificuldade. $\mathrm{O}$ funcionamento lógico de uma linguagem tem uma dose de influência sobre como ela obriga os seus falantes a construir proposições significativas. Mas há no DNA científico ocidental o medo de que essa obrigação possa ser reconstruída como uma teoria deontológica sobre a necessidade e que possamos projetar sobre o mundo externo os elementos antropomórficos contidos em nossa gramática. A transição da tese da obrigação lógica para uma teoria modal parece resgatar o essencialismo para o interior da ciência, e nos levar a uma época 
que está injustamente proibida de usufruir das vantagens das reflexões de Hume sobre a indiferença da matéria de fato aos nossos sistemas lógico-vazios, convertendo uma limitação humana - "porque estamos limitados a adaptar qualquer padrão alheio ao nosso padrão" (QUINE, 1980, p. 117) - em regra transcendental ou pragmática-normativa.

Essa divisão, portanto, tem que ser rediscutida se alguém acredita que disso depende reabilitar a questão das intensões sem cair em uma nova-metafísica ou sistema antropomórfico. Uma linguagem, teoria, ou modelo analógico-estrutural para predição de sentenças, pode ter um repertório técnico mais ou menos bem adaptado para que suas construções de identidade referencial sejam logicamente responsáveis - isto é, respondam a pressões lógicas. Chamamos uma construção de identidade intensional, em vez de extensional, simplesmente por ser melhor entrincheirada tecnicamente, ou por possibilitar uma defesa mais forte de sua demonstrabilidade. Isso implica a sugestão de que as sentenças as quais Quine diria estar em uma posição mais central de um sistema linguístico veiculariam uma força intensional ${ }^{6}$. O problema, para o pensador americano, é que confundimos, no interior da linguagem, essa força, derivada principalmente das teorias científicas que abastecem as identificações e classificações pertinentes, com uma espécie de superestrutura modal criada, alimentada e preservada pela própria linguagem enquanto mecanismo de referência. Haveria a reificação de um objeto criado pela linguagem em consórcio com a ciência. Quine não rejeita a ideia de que aumentamos a capacidade de deduzir enunciados através do conteúdo emprestado de teorias científicas. Ele questiona que esse conteúdo forneça motivos normativos para construir uma metafísica da experiência, uma esfera de conhecimento não-revisável. A lei de Leibniz varia de força se nossa linguagem está mais madura tecnicamente para não deixar nenhum nome em zonas de classificação cinzenta, mas isso é um enriquecimento da linguagem que é feito pela ciência empírica de seu tempo e não por uma investigação metafísica das próprias coisas referidas.

Mas, embora a crítica de Quine pareça justa pela perspectiva do empirismo e suas conquistas ameaçadas, ela é intolerante contra outras formas - não particularmente metafísicas - de lidar com o conceito de intensão. Há todo um universo de pensamento anti-metafísico simplesmente negligenciado pelos herdeiros do positivismo e da filosofia analítica. Uma inclinação cega a pensarem a si mesmos como única frente de oposição à metafísica levou a filosofia a essa inconveniente versão simplificada da própria metafísica. Vamos observar algumas das questões que não surgem ou sequer são percebidas como tais por Quine. $\mathrm{O}$

\footnotetext{
${ }^{6}$ Em Dois Dogmas: "uma experiência recalcitrante pode, eu salientei, ser ajustada por qualquer uma das várias reavaliações alternativas em vários setores alternativos do sistema global" (1980, p. 246).
} 
pensador americano não parece levar em conta que a força das equivalências e critérios classificatórios da linguagem não é preservada sem perda quando os relegamos à responsabilidade de teorias científicas. A tentativa de reduzir a força intensional de uma conexão a uma correlação extensional é análoga ao enfraquecimento do entrincheiramento técnico conquistado por uma linguagem, e só é vantajosa em meio a projetos de revisão científica ou redução de campos de estudos - como a Biologia - a outros - como a Física teórica. Essa vantagem desaparece se julgarmos os nossos propósitos comunicativos e a estabilidade de nossas interpretações na sua globalidade, isto é, se precisamos julgar proposições verdadeiras sem julgar teorias científicas específicas. A redução extensional é uma tentativa de comparar linguagens diferentes indiferentemente do perfil de projeção profundo de cada uma delas. Em outras palavras, é um projeto de redução da linguagem à sua superfície estrutural.

\section{Conclusão: a força das pressões identificadoras da Linguagem e uma teoria da Intensão coordenada a tradições hermenêuticas}

Um esquadrinhamento rápido da literatura sobre a intensionalidade descobrirá que a maior parte da aversão fácil que foi difundida contra as intensões se deve à associação que invoca as sinonímias como exemplo paradigmático de relação de identidade interna à língua ${ }^{7}$, e a analiticidade como o modelo padrão de necessidade lógica convertida em traço normativo da linguagem. No entanto, as sinonímias são as formas mais superficiais e mais próximas à extensionalidade de identidade. Os dicionários são pouco respeitados como reguladores de transações hermenêuticas, mesmo entre os exegetas mais dogmáticos, justamente por isso: eles se referem às correlações identificadoras in abstrato, sem observar a divergência de força concreta (a ênfase) que certas substituições podem promover às alternativas de substituição sinonímicas. A força interna de um texto canônico costuma ser ligada a fontes normativas de pressão identitária (categorias) mais consolidadas do que as lexicográficas. Um texto tradicional engorda ou inflaciona intencionalmente graças ao histórico de suas interpretações, e não por uma discussão lexicográfica. $\mathrm{O}$ que não se percebe a respeito das sinonímias é que elas representam apenas as formas de identificação cuja força intensional já é fraca o bastante para uma representação numérica ou um automatismo analógico. Por isso, no limite, mesmo máquinas podem reproduzir essas identificações. Mas a linguagem operada por seres humanas

\footnotetext{
${ }^{7}$ Nos referimos principalmente à versão carnapiana do conceito de intensão. Ver Significado e Sinonímia nas Linguagens Naturais: "o propósito desse trabalho é esclarecer a natureza do conceito pragmático de intensão nas linguagens naturais e esboçar para ele um procedimento operacional, behaviorista" (Carnap, 1980, p. 131)
} 
é mais complexa. Na medida em que uma língua entrincheira suas identidades mais profundas junto com seu aumento de compreensão teórica - gramatical, lexicográfica, etimológica, etc. é possível dizer que os sinônimos são a parte menos consciente ou teórica dessa compreensão (menos conscientes). Dificilmente vemos dicionários se tornando textos canônicos de uma cultura, e existe um motivo não acidental para isso. Na verdade, os textos canônicos de uma cultura são aqueles que são mais traduzidos, ou que atraem maior intercâmbio interpretativo; mas a relação dos dicionários com o mercado das traduções e interpretações domésticas é outra: eles oferecem modelos de comparação e de simplificação, deixando a correlação mais próxima da extensionalidade.

A segunda forma típica com que se considerou a questão foi a analiticidade, a famosa verdade em virtude da identidade dos conceitos ou do significado interno aos termos ligados. Mas aqui também temos uma codificação superficial da codificação intensional da língua. A verdade analítica é a expressão normativa de uma verdade lógica. Ela é o modo como uma intensão seria qualificada no caso raro em que é traduzível por uma verdade lógica, e traduz essa logicidade para a sua expressão mais semelhante ao perfil-normativo da linguagem em questão. Dizer que uma verdade é analítica é dar um carimbo normativo para uma conexão necessária que a linguagem consegue derivar sem consumir recursos codificadores insustentáveis ou ameaçar a estabilidade de seu centro codificador. Nessa configuração, o conteúdo intensional também simula o extensional. Ele pretende obrigar a linguagem a se comportar verifuncionalmente, ou criar o padrão normativo que a assemelharia ao máximo a uma distinção lógica.

Tanto a sinonímia quanto a analiticidade são representações injustas, incompletas ou estereotipadas da verdadeira força da inércia intensional que controla a codificação da identidade em uma linguagem. Em vez de pensá-la nessas expressões lógicas ou gramaticais maduras, devemos abrir a compreensão das intensões simplesmente para abranger todo o potencial normativo da linguagem, ou suas pressões internas a padrões identificadores homogêneos. Uma linguagem não tende a se fortalecer intensionalmente por uma suposta necessidade lógica reificada, mas por uma inércia institucional ou resistência a outras mediações linguísticas que constroem apoios de implicação ou suportes para facilitar inferências. A ideia de síntese a priori, ligeiramente adaptada de seu formato kantiano original, faz uma justiça maior ao conceito de intensão do que o par sinonímia/analítico, uma vez que representa a força das categorias para pressionar as identificações conceituais a direções 
unificadoras $^{8}$. Uma síntese a priori tem a vantagem, sobre a analiticidade e a sinonímia, de manter a codificação linguística aberta a configurações esquemáticas novas e contrapressões codificadoras. Isso se mantém verdadeiro para além de Kant; isto é, ainda que a crença de Kant em um mundo completamente esgotado pelas leis de Newton o levasse a determinar o domínio da esquematização intensional como um domínio tão fechado de possibilidades e conexões quanto o analítico.

\section{Apêndice: Husserl e a codificação sintética como mediação intensional dos signos}

A principal diferença entre o que chamamos de linguagem e uma teoria sobre o significado é que a primeira codifica em signos as teses sobre a identidade que usamos para solucionar problemas de referência. Um problema de referência é solucionado por uma teoria semântica que atribui à proposição uma fatia da realidade que a suporta junto com todas as suas implicações. Ela cria uma linha de apoio mínimo da realidade que não pode aumentar na direção oposta, da mesma forma que um sample suficientemente grande de uma pesquisa estatística não pode aumentar contrabalançando a conclusão indutiva na direção oposta (isto é, o sample estatístico não pode aumentar apoiando uma proposição que contradiz essa conclusão). Um signo codifica essa relação atributiva e dá a impressão, assim, de que a teoria intensional que classifica as diferenças semânticas (ou que organiza a confirmabilidade das proposições) é uma representação simbólica capaz de invocar a referência ou reconhecê-la em qualquer circunstância. Importante notar que a referência não é qualquer complexo de realidade, mas apenas a parcela de realidade organizada semanticamente para responder a uma hipótese sobre a verdade de uma sentença, como o sample estatístico. Isto é, a referência é aquele recorte de mundo externo que responde positiva ou negativamente à seguinte hipótese: a de que a plataforma de apoio de que uma sentença depende transmite o mesmo apoio a todas as sentenças estabelecidas nessa mesma plataforma de dependência. O que a codificação semiótica traz de novo ao problema da referência é apenas a padronização normativa da identificação do recobrimento.

8 Ver Immanuel Kant (KrV A 79 /B 104): “A síntese pura, representada de uma maneira universal, dá o conceito puro do entendimento. Entendo, porém, por esta síntese, que assenta sobre um fundamento da unidade sintética $a$ priori :assim, a nossa numeração é uma síntese segundo conceitos (o que é sobretudo evidente nos números elevados), porque se processa segundo um fundamento comum da unidade (o da dezena, por exemplo). Sob este conceito é, pois, necessária a unidade da síntese do diverso" (2001). 
Na Sexta Investigação de Husserl, temos testemunha de uma preocupação análoga. Em um sistema de pensamento aparentemente distante, é sintomático que essa questão foi pensada de modo semelhante. Debatendo como intenções signitivas são preenchidas por intenções intuitivas, Husserl está percorrendo um tema complexo da filosofia, que pode ser aproveitado tanto para uma discussão da questão da "confirmação" quanto da "compatibilidade" entre classes de possibilidades. Refletindo sobre a relação da palavra e o tinteiro, ele afirma que "enquanto nomeia, essa relação é mediatizada não apenas pelos atos de significar, mas também pelos de conhecer, que aqui, aliás, são atos de classificação" (1988, p. 24). O autor acredita que "a identidade mais ou menos perfeita, é o objetivo que corresponde ao ato de preenchimento" (1988, p. 31). Exprime-se nesses trechos a percepção de que o problema em que estamos envolvidos quando procuramos um fundamento comum para um grupo de compatibilidades é este: achar a matéria que perfaz ou classifica a unidade do apoio às proposições verdadeiras que elas suportam. Essa notificação é importante para localizar o debate sobre como se dá uma codificação em torno do potencial lógico de uma estrutura cumulativa de conhecimento. Para Husserl, "temos razões para designar como visualizações propriamente ditas não aquela que recheia de uma maneira qualquer, mas exclusivamente aquela que traz um aumento de recheio para o objeto representado" (1988, p. 58). No entanto, "nem sempre (...) as matérias dos dois lados (...) estão na relação de recobrimento" (Husserl, 1988, p. 59). O que liga o problema das compatibilidades ao problema do recobrimento que enriquece uma intenção sugere - contra Kripke - que há uma solução unificada ao problema epistêmico e ao semântico, no sentido de que a correção de um juízo é tanto uma proposição verdadeira quanto um ajuste de possibilidades relevantes para completar a representação de um conhecimento.

Cada língua natural ou sistema de signos é um médium que contém todas as nossas teorias sobre a identidade, desde o nível ostensivo até os níveis simbólicos mais complexos. A simplificação ontológica requerida para o funcionamento da relação estrutural semântica ganha, no código, uma expressão portátil, junto com uma carga inercial capaz de se antropomorfizar reunir as conquistas humanas em um sistema analógico, metafórico, metonímico.

O que uma abordagem feita diretamente sobre o código traz é uma explicação do centro de ampliação uniforme de uma linguagem, seu modo de controlar a inflação inevitável derivada de sua entrada no mercado de verdade. Existe uma inflação inevitável, uma inversão do reducionismo, quando uma teoria científica é representada pela semântica de uma linguagem, quer chamemos essa conversão da ciência em uma teoria sobre o significado, quer a tratemos como uma conceitualização tácita incrustrada nos códigos e símbolos. A identidade que subsiste 
sem mediação, sem carga intensional, é também uma identidade superficial. É essa inflação que constitui o campo de ação e ampliação intensional. Para abordar esse tema, uma opção direta que aproveita o campo de doutrinas filosóficas disponível é uma teoria das sínteses. A codificação da síntese é um protótipo da codificação semiótica. Ela envolve a proposição 1. de que a percepção é uma versão imediata de uma codificação feita pelo médium formal (que pode se tornar linguístico ou não a depender de seu amadurecimento institucional) e 2 . de que a redução de uma linguagem a outra em termos extensionais envolve o obscurecimento ou a mistificação da relação de correlação, isto é, envolve uma correlação não mediada, onde as perdas na tradução são compensadas por um critério de violência ou colonização (ganha a língua mais forte).

\section{REFERÊNCIAS BIBLIOGRÁFICAS}

CARNAP, R. Textos Escolhidos. São Paulo: Abril Cultural, 1980.

DUMMET, M. Origins of Analytical Philosophy. Cambridge, Harvard University Press 1993.

DUMMETT, M. The Interpretation of Frege's Philosophy. Cambridge, Harvard University Press, 1981.

ETCHEMENDY, J. The Concept of Logical Consequence. CSLI Publications. 1999.

HAACK, S. Filosofia das Lógicas. São Paulo: Editora Unesp, 2002.

HUSSERL, Investigações Lógicas: Sexta Investigação, São Paulo: Abril Cultural, 1988.

MARCUS BARCAN, R. Modalities. Oxford University Press: 1993.

KANT, I. Crítica da Razão Pura. Fundação Calouste Gulbenkian: Lisboa, 2001.

KRIPKE, C.I. Naming and Necessity. Harvard Press, 2001.

QUINE, W.V.O. Relatividade Ontológica e outros Ensaios. Ensaios. São Paulo: Abril Cultural, 1980.

QUINE, W.V.O. The Ways of Paradox. Cambridge, Harvard University Press, 1994.

RUSSELL, Da Denotação, Lógica e Conhecimento, São Paulo: Abril Cultural, 1978. 